\title{
Los hilos de lo desconocido: Luzbel, de Gonzalo Arias Páez
}

\author{
Gabriel Baltodano Román
}

Universidad Nacional de Costa Rica

Un libro es una cosa entre las cosas, un l'olumen perdido entre los volumenes que pueblan el indiferente universo, hasta que da con su lector, con el hombre destinado a sus símbolos. Ocurre entonces la

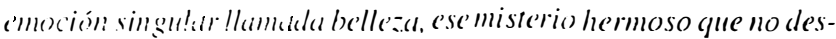
cifran ni la psicología ni la retórica.

Jorge Luis Borges

Cada anaquel resguarda, soporta el peso de los libros y de la ceniza abandonada encima de éstos por el tiempo que se consume; atesora por igual impresos y estampas cuyos buenos nombres brindan amparo de por sí, y tomillos endebles. Una biblioteca es luego, un mundo desigual; en sus pasillos coexisten, bajo el desconcierto, diversas creaciones; las hay joviales, marchitas y solemnes, algunas han caído, las más ni siquiera conocen los albores del aire.

Nunca se sabe bien con claridad cuáles títulos cederán ante la agitación de cada era — náufragos en un mar de palabras — y cuáles se sobrepondrán a los desiertos que teje el polvo afanoso. Sin embargo, una biblioteca simboliza la natural imposición del sentido común o del azar: muchos libros, condenados a arder en el olvido, redimen su pena en el estante, aguardan en éste por días mejores. Y es que, aún cuando difieren entre sí, tratan de aclarar el mismo turbio enigma: ¿qué somos? El acto que engendra al libro está cargado de soberbia; en altiva sinécdoque grita con desmesura: yo soy lo humano. Cada libro actúa como un trozo de cristal que espera por nosotros, ha sido puesto allí por otras mentes en épocas disímiles; es el fragmento del espejo donde el mundo se mira roto, pero se mira. 
Quien enciende una vela libera un alma del purgatorio, reza la pauta aprendida durante la niñez; afirmación, por lo demás, un tanto exagerada en sus implicaciones. Aún así, en esta ocasión, el comentario de una lectura reciente of rece la oportunidad de traer a la memoria el caso de una obra desconocida. De alguna manera se llega siempre al volumen indicado; esta vez es uno delgadísimo, la envejecida mirada que se descubre en su carátula debe el origen a la pluma de Manuel de la Cruz González, su ilustrador; el título resulta sencillísimo de recordar: Luzbel'.

En el panorama general de la literatura costarricense, como en el de cualquier otra, conviene asumir con prudencia cierta especie de hallazgos; no se acude al comentario de una obra indispensable si se desea captar el avance de las letras nacionales, pero tampoco al de un texto ordinario. Escaso provecho otorga el imaginar que se está ante una escritura límite, a pesar de la extrañeza que suscitan no sólo las temáticas sino la prosa poética y los diálogos a modo de confidencia. La importancia de una obra radica no siempre en la novedad o en la ruptura con lo establecido; a menudo, se presume que el valor de un objeto artístico proviene de su singularidad; al hacer esto, se relega la idea de continuo, se la subordina ante un criterio común entre los creadores, pero poco útil en los estudios literarios, a saber, el ingenio excepcional.

De entrada, no se trata de desestimar el talento patente en esta colección de relatos, su diáfana presencia no puede negarse, como tampoco admite reservas el hecho de que su propia naturaleza lo hace impenetrable; se procura, pues, sustraer el problema, cercarlo mediante la racionalidad; para esto, se piensa en la constancia, en el desarrollo

1. Gonzaio Arias Páez. Luzbel (San José: Editorial Costa Rica. 1969). Se trata de una colección de cuentos compuesta por siete relatos. Gonzalo Arias Páez. quen aunque nació en México. de padres costarricenses. en 1945. vivió desde la niñez en nuestro país y participó de la actividad cultural del Círculo de Escritores Costarricenses. Ésta es la única edición de la obra. la publicada como parte de la Colecición La Propia por la Editorial Costa Rica e impresa por Trejos Hermanos. Deseo agradecer al doctor Carlos Francisco Monge por su acertada recomendación bibliográfica. punto de partida del presente artículo. 
del lenguaje literario. Se comprende, entonces, que en el entre donde se sitúa el libro, en el intersticio de la historia literaria se halla la clave. La aspiración de estas páginas se revela: disertar acerca de un texto periférico en el discurso nacional y que, sin embargo, resulta interesante en al menos dos sentidos: primero, por su considerable valor estético en relación con la escritura de la época; segundo, porque induce a preguntar cuáles son las condiciones culturales que explican esa clase de inadvertencias.

Además, el examen de obras como Luzbel permite una mejor comprensión de la literatura nacional, puesto que aclara algunas preocupaciones propias de los escritores contemporáneos; Gonzalo Arias Páez podría ser ubicado, en función de su edad y de sus vivencias particulares, como parte de un grupo de artistas costarricenses cuyo período de formación coincide con los cambios culturales ligados al triunfo de la Revolución Cubana y que participó de las revueltas estudiantiles en nuestro país. Tal generación estaría compuesta, en opinión de Álvaro Quesada ${ }^{2}$, por los narradores Fernando Durán Ayanegui (1939), Quince Duncan (1940), Alfonso Chase (1945), Gerardo César Hurtado (1949); los poetas Jorge Debravo (19381967), Mayra Jiménez (1938), Laureano Albán (1942) —quien edita Luzbel_, Julieta Dobles Yzaguirre (1943), Rodrigo Quirós (19441997), Carlos de la Ossa (1946); y los dramaturgos Antonio Iglesias (1943) y William Reuben (1947).

En estos autores es usual la recurrencia a tópicos asociados con la búsqueda de la identidad; por lo general, las obras narrativas —-donde se insiste en este motivo- plantean un mundo extraño u hostil, cuyos valores se contraponen a los del joven protagonista, éste debe forjarse un temperamento que le permita enfrentar el mundo desde su subjetividad. Predominan en los relatos la soledad, el desarraigo, la incomunicación y el rechazo al orden social o a la tradición familiar,

2. Álvaro Quesada Soto. Bre've historia de la literatura costarrice'tuse' (San José: Porvenir, 2000) 70-71. 
ajenos a la vida y creencias de los personajes centrales. $\mathrm{Al}$ respecto Quesada escribe:

En toda la narrativa de esta época se profundiza la brecha, que se había venido ensanchando a lo largo de la historia literaria costarricense, entre subjetividad y orden social. Las instancias del poder, sus mecanismos de dominación o enajenación, se manifiestan cada vez más difíciles de determinar y representar pues pasan de identificarse con figuras o instituciones fácilmente ubicables en el mundo objetivo - como el estado, el mercado, el latifundio, las bananeras- a identificarse con estructuras más difíciles de percibir conscientemente, pero igualmente represivas u omnímodas — como el patriarcalismo, la burocracia o los sistemas de control ideológico-que tienden a trasladar los conflictos desde la realidad objetiva a la subjetividad misma del personaje ${ }^{3}$.

El discurso literario elaborado por este círculo de creadores se torna cada vez más complejo en vista de las alteraciones culturales experimentadas durante este período; la modernización del país, en manos de los ideólogos de la Segunda República, supuso la apropiación de asuntos inexplorados y la puesta en marcha de una literatura introspectiva. Cierto ludismo estético y el afán por abordar el problema de la identidad desde lo fantástico, línea expresiva poco común en las letras anteriores, responden a un intento por borrar las rígidas convenciones que determinaban los límites de la vida personal y social; además de proporcionar nuevos modelos artísticos de acercamiento a las condiciones psicológicas del individuo y de la colectividad.

La literatura costarricense experimenta, a lo largo del siglo XX, un progreso que aleja a sus jóvenes criaturas, cada vez más, de una cierta tradición. Frente a las categorías cerradas, surge la indeterminación,

3.

Quesada. 73. 
perspectiva absolutamente contemporánea; ante las férreas distinciones entre uno y los otros, el tiempo y el espacio, lo serio y lo cómico, lo trascendente y lo intrascendente, lo propio y lo ajeno, lo real y lo imaginario, entre objetividad y subjetividad, surgen ámbitos donde es imposible distinguir las fronteras. Semejante proceso ha sido causado por las modificaciones que generó la inclusión de lo moderno en los esquemas mentales, por el crecimiento urbano y el influjo de las metrópolis occidentales sobre nuestra nación. El auge y la decadencia que siguieron a la guerra civil de 1948 alimentan la experiencia de esta generación; el mundo es inconstante, las esperanzas reformistas decaen conforme avanza la segunda mitad del siglo y los lanzan, en términos espirituales y epistemológicos, hacia el escepticismo, el desencanto y la introversión, a un mundo enajenado.

«Cada vez es más difícil abstraerse a la sensación de opresión ante un poder que no se logra localizar o al temor ante las amenazas del desastre ecológico, el sida o la violencia. Incluso, se habla de la muerte de la metafísica, el humanismo y el arte, del fin de las utopías que fundan un centro u otorgan un sentido a la existencia», señalan Flora Ovares y Margarita Rojas al determinar las cuestiones prioritarias de esta generación y su sentir ${ }^{4}$. Se podría recurrir a esta premisa para descifrar varias narraciones compendiadas en Luzbel.

«El infierno», una de estas narraciones, describe con exactitud la arquitectura del averno; la angustia experimentada por Marcelo Giannini, el condenado, procede de la simetría, del endemoniado esmero matemático con que ha sido construida su cárcel. Tras asesinar a cuchilladas sin razón alguna a un viejo, Giannini muere en manos de la turba que con indignación observó el crimen; su llegada a los infiernos es inmediata; al principio, siente satisfacción debido a su morboso afán por saber si existe o no el lugar donde penan las almas; luego, teme. El tiempo borra sus miedos y lanza al italiano a una exploración infructuosa, una y otra vez las mismas paredes y columnas,

4 Flora Ovares y Margarita Rojas. 100 años de literatura costarricense (San José: Farben, 1995) 211. 
la pulcritud y lo idéntico componen su terrible castigo; a Giannini le aterra lo mismo: «En la agonía solitaria de lo infinito dejé a veces de tener conciencia de que existía» (18), apunta el protagonista en su diario.

Tal historia, contada en primera persona como se ha advertido ya, llega a manos del público, según cuenta el prólogo — articulado por otra voz narrativa, voz impersonal que se confunde con la instancia del autor y que nos hace creer en la veridicción del relato. El efecto se acentúa si se considera la fecha del hallazgo, cercana a la publicación de Luzbel-, mediante una carta del orientalista Gregorio Hunt enviada en noviembre de 1964. Hunt habría descubierto el manuscrito de Giannini entre los papeles que dejó al morir el historiador italiano F.R. Cammarotta. Después de traducirlo, el narrador nos lo presenta; tal disposición retórica sigue la clásica presentación cervantina. El juego especular engendrado por medio de la inserción de un texto en otro genera, en tanto recurso semiótico, la misma impresión: se reseña un hecho real, que ha impactado al escritor y justifica la aparición del libro como esfuerzo por ahondar en lo insólito, libro cuyo inicio precisamente es esta historia y este ardid.

En «Pekín» se sugiere la presencia del infierno en el mundo de los vivos; éste sería el resultado de las sistemáticas persecuciones políticas propiciadas por el totalitarismo. Julián Barentz, acusado de pegar propaganda en los muros de la ciudad, es llevado a la oficina de la policía secreta; tras el interrogatorio, le conducen a la «clínica» donde curarán su desviación ideológica, su enfermedad mental. De nuevo, el castigo se concibe como la anulación de lo diferente; hacer de Barentz un comprometido con el partido equivale a convertirlo en otro, a revertir su identidad, a enajenarlo. Sin duda, tal proceso deriva en una ardua labor; ni siquiera la represión física disuade al infractor, su pecado es el mismo de Luzbel: se ha rebelado contra el orden, contra lo uno. Incluso el método correctivo se parece, consiste en inutilizar la subjetividad llevándola a sus límites de tolerancia: 
Le llevaron a un edificio grande, situado en las afueras de la ciudad, advirtiéndole que le harían un tratamiento sencillo (le dijeron), pero efectivo; y le dejaron en una habitación sin luz. [...] Se percató de que aquel lugar estaba acondicionado con intención tan definida que hasta él no llegaba ningún sonido del exterior, siendo la oscuridad perfecta. Sentía esa oscuridad rodearle, flotando en el silencioso ropón tibio que envolvía la estancia, en cuyo centro, y por único mueble, había una cama espaciosa (68).

Tanto el demonio infernal como los censores desaparecen de la escena; no obstante, su presencia ubicua queda demostrada en la vileza del escarmiento; ésta cobra la forma del espacio, sitio para el dolor, lugar de lo absoluto y extremo; a la luminosidad enceguecedora del averno se oponen las tinieblas de la celda; a la inmensidad de lo infinito, la pequeñez, lo reducido y el confinamiento. Siempre las formas únicas, nunca la diversidad. Hacia el final del cuento, Barentz vislumbra cómo el objetivo de sus captores estriba en sembrar la desconfianza y la traición entre los transgresores, en destruir sus nexos en tanto comunidad divergente; el hambre desempeña un rol fundamental en este mecanismo, los deshumaniza, los convierte en bestias manipulables. Si Giannini ha perdido toda relación con su cuerpo, nada siente, nada demanda su naturaleza anulada por la mente; Barentz, por el contrario, víctima del pensamiento, deviene en instinto puro de supervivencia. En ambos casos, dominar equivale a reducir. Así, la indagación acerca de la identidad de las cosas y los seres deviene en fundamento del pensamiento artístico en Luzbel; se expresa, a menudo, mediante la exploración fantástica. Algunos textos atienden la faceta social del problema; otros, la individual. Incumbe al estudio de esta obra la aproximación fantástica al problema de la identidad, pues explica sus conexiones con la producción literaria de la generación en la que se sitúa; a la vez, subraya su diferencia con respecto a ésta: en el libro de Gonzalo Arias se tratan ciertas cuestiones 
de base para los escritores contemporáneos, pero el tratamiento difiere de las formas habituales por cuanto acude a lo fantástico.

Valga mencionar que tanto Giannini como Barentz, al igual que otros muchos personajes, sueñan durante el cautiverio; esto introduce una duda razonable con respecto a la fuente del conflicto, es decir, complica la localización de las opresiones sobre el sujeto, pues, por una parte, si fueran vivencia provendrían del mundo objetivo y, por otra, si fueran ensueño tendrían por lugar la interioridad misma que atacan. Lo fantástico implica la vacilación del personaje y del receptor. En este caso, indudablemente, la literatura fantástica posibilita una especulación sobre lo real, pues, como explica Rosemary Jackson,

Fantasy re-combines and inverts the real, but it does not escape it: it exists in a parasitical or symbiotic relation to the real. The fantastic cannot exist independently of that «real» world which it seems to find so frustratingly finite ${ }^{5}$.

Para decir lo impensable, para expresar «el código de principios subyacentes a una época dada y para una cultura determinada» ${ }^{6}$, es decir, para enunciar o hacer conscientes las certezas no racionales que hacen posible el pensamiento, los fabuladores acuden a la invención de pequeños uni versos, que si bien se alejan aparentemente de la realidad, pretenden, por el contrario, acercarse a ésta de un modo más profundo.

Tales mundos son, en alto grado, metáforas epistemológicas acerca de la realidad. La ruptura de lo único y la consecuente ambivalencia que componen el retrato de la mentalidad contemporánea se manifiestan en Luzbel a través de una serie de imágenes; cada uno de

5. Rosemary Jackson, Fantasy: The literanure of Subversion (Londres: Routledge, 1988) 20.

6. Carlos Rojas Osorio define de esta manera episteme en Foucault y el posmodernisimo (Heredia: Universidad Nacional-Departamento de Filosofía. 2001) 42. Tal noción resulta extremadamente útil. pues nos permite explicar la manera particular en que lo fantástico recurre al «inconsciente» del pensamiento. Si el deseo funda la realidad humana y el deseo, como explica Foucault en El orden del disc'urso (Barcelona: Tusquets. 1983) 12, tiene por lugar el discurso: entonces, el discurso fantástico expresa la más honda realidad humana: aquélla que desconoce. 
los relatos, aún cuando ninguno apunta temáticamente hacia lo costarricense, insinúa una crisis moderna que atraviesa también lo nacional. De tal forma, la elección misma del discurso fantástico involucra una ruptura de los tópicos comunes al campo literario nacional, pero también un retorno a su sentir. Esa aspiración, que inicia con los modernistas y deviene preeminente para Hispanoamérica con las vanguardias, por ensanchar las miras de lo autóctono, por emparentar nuestras letras con lo cosmopolita, con lo occidental, acaba, en el libro de Arias Páez, por revertirse, por desandar el sendero que guiaba hacia los confines de las letras costarricenses.

La rebelión da lugar al fracaso, frente a éste la conciencia experimenta un doloroso regocijo; el ángel cae por separarse del Padre, su historia es la de aquél que reniega del autor para convertirse en dueño de sí, en propietario de sus miserias. Uno de los relatos, el que da nombre al libro — «Luzbel»—, trata justamente acerca de esto. La historia tiene por espacio, resulta obvio, el paraíso; el lector advierte, en función de su competencia textual, que se aproxima una desgracia, el paisaje natural — mundo telúrico y en ese mismo sentido, mundo de la interioridad - recalca todo indicio de tribulación:

Descendió la luz y surgieron, como si hubiesen venido con ella los valles y los ríos. Las raíces se escondieron en la tierra huyendo del canto del pájaro, temerosas de la caricia del sol, ramificándose, expandiéndose, erizándose en forma de lluvia, en ondulantes barbillas, tejiendo en lo profundo la orla de luz de las rosas blancas, la carne de jazmines y azaleas que flotan en el aire como manchas de sangre combadas y frías; tejiendo en lo profundo la efervescencia de las enredaderas, libando la miel que reposa en el seno de la tierra, bebiendo del agua de lluvia que desciende a ellas y llevando la luz de las estrellas. Las raíces llegaron donde se oculta el oro y éste se escurrió asustado entre las grietas. le siguieron tirando en todas direcciones las redes. Se retorcían de angustia, se hundían. Ilegaban a 
los rincones más alejados, más allá de las arenas, más allá del cuarzo, deslizándose sobre el frío cuerpo de los mármoles, deslizándose sobre las aguas subterráneas, sobre las masas de piedra, por entre las grietas (39-40) (los destacados son nuestros).

Se destacan las formas verbales asociadas al sujeto, raíces, pues explican, en primer término, la idea que se sostenía unas pocas líneas arriba - basta con considerar la naturaleza semántica de voces tales como esconderse, huir, erizarse y retorcerse de angustia-; en segundo término, articulan una acción progresiva: el descenso. El movimiento hacia abajo no difiere de la caída; las raíces anuncian, mediante la simetría, el destino del protagonista; ahora bien, tal caída no conlleva un menoscabo; al igual que las raíces, Luzbel se lanza al abismo en pos de la vida, de su ser; la suya es una búsqueda en lo profundo y oscuro, que definen su naturaleza.

Justamente en la materia halla Luzbel lo que le distingue de Dios, la palabra pura, la trascendencia; sus compañeros, los ángeles recelosos, acusan al que se ha separado, pues opinan que la verdad ha huido de su boca; éste vocifera:

-No saben que en sus cuerpos se desliza la sangre pegajosa, tibia, no saben que están hechos de madera blanca, de músculos rojos como el fuego, no saben que están hechos de esponjas y ojos de pescado, ignoran que están amarrados con lianas y con tallos de loto, no saben que en sus cabezas flota la carne de un animal milenario, replegado a sí mismo, hecho de agua de mar y carne de almejas (42-43).

Conforme avanza el relato, Luzbel cobra mayor conciencia acerca de la distancia que lo separa de las demás creaciones; sólo él ha entendido su condición y, por tanto, puede liberarse de las ataduras de la enajenación. del ser en otro; proclama entonces: 
- ¡Soy Luzbel!- Gritó rasgando el silencio y despertó a los guacamayos. iiiMillares de guacamayos y pericos comenzaron a revolotear sobre el ramaje, gravitando en el abismo como si se hubiesen quedado dormidos, saciando la sed de belleza de Dios!!! Comenzaron a cantar. Millares de guacamayos cantaban y decían... Soy Luzbel... soy Luzbel... Luzbel... (46-47).

No obstante, la afirmación de su identidad no riñe, a diferencia del relato bíblico, con la existencia de Lo Absoluto; hacia el final del cuento, Dios se aproxima a Luzbel, se arrodilla y besa sus pies. En ese instante, el ángel rebelde advierte que su creador «le definía sin deformarlo, lo ubicaba sin humillarlo, lo iluminaba sin cegarlo» (49); que bendecía su arrogancia, pues alejaba la soledad que embarga todo. El ángel llora luz y Dios realiza su sueño siguiendo el modelo dado por Luzbel: crea a los hombres.

En algún momento, se sugirió que las imágenes contenidas en esta obra desempeñaban las funciones de metáforas, grandes metáforas epistemológicas acerca de la condición humana; por supuesto que esto nada tiene de extraño, generalmente, la literatura opera así. La singularidad estriba en que estas metáforas apuntan hacia un mismo asunto: nociones modernas de la identidad.

En el libro de Arias, el pensamiento artístico coincide con la especulación lógica. Al debatir la concepción filosófica de individuo, Luce Irigaray pasa revista a las resoluciones de los antiguos y de los modernos (Hegel, Kant, Heidegger, Sartre y Merleau-Ponty); pronto descubre que el sujeto se desarrolla a partir de una pugna, de una tensión, entre entes opuestos: en un extremo, está él; en el polo opuesto, Lo trascendente, El Otro o un objeto. Irigaray señala cómo la dualidad funda, de acuerdo con la tradición occidental, la conciencia humana, distante de todo esfuerzo por concertar la razón y el cuerpo, sustraída del encuentro con el otro en tanto sujeto y en aras de la posesión que reduce a los demás a la pasividad de las cosas? ${ }^{7}$.

7 Luce Irigaray, Ser dos (Buenos Aires: Paidós. 1998) 103-112. 
Quizá la tendencia a armonizar los diversos componentes de la identidad que se presenta en Luzbel corresponda con las concepciones orientales de los vínculos entre el ser y la conciencia, el Yo y el otro. Debe recordarse que durante la década de los sesenta, como resultado de los movimientos pacifistas y la aparición de las agrupaciones hippies, muchos jóvenes tuvieron contacto con tales ideas; en Costa Rica, ya en los años treinta, Brenes Mesén había dedicado grandes esfuerzos intelectuales al estudio y difusión del orientalismo. A modo de guiño, supongo, aparece el loto en «Luzbel»; basta con mencionar que tal flor, de acuerdo con los Upanisad del yoga y los Yogasîtras, es objeto de la mirada de Buda, una mirada singular, pues se basa en el respeto de lo que no le pertenece, en el placer de lo otro, en la comunión con lo que no es parte del yo mediante la contemplación meditativa, la no violencia y la negación de conductas depredadoras. La mirada de Buda sobre la flor brinda una posible comprensión de la identidad y la alteridad que se aleja radicalmente de la occidental.

Precisamente, las reiteradas menciones a los actos de ver, observar y contemplar señalan la existencia de una isotopía que estructura el relato titulado «Narciso». Al igual que Buda, el protagonista, símbolo mítico de las dificultades que provocan los enfrentamientos de lo idéntico con lo diverso y de lo objetivo con lo subjetivo, mira las flores con desprendimiento; su atención divaga por senderos abigarrados, los de su propia conciencia. Sujeto y objeto de sus especulaciones, Narciso abrumado se piensa; presa de su deseo, procura un otroél que le permita visualizarse con mayor claridad ${ }^{8}$. Así, incapaz de escuchar a los demás, atiende tan sólo a la profecía del sueño, a la voz de su interior que le resulta, a la vez, suya y ajena:

8. El narcisismo. tal y como lo propone el psicoanálisis freudiano. implica un proceso de evolución que va desde el autoerotismo - narcisismo primario- hasta la elección de un objeto — narcisismc secundario-; a la catexis de la libido. sigue ìa apropiación objetal. Ver Jean Laplanche y JeanBertrand Pontalis. Diccionario de psicoanálisis (Barceiona: Labor. 1993) 228-232. 
Vio las aguas del lago tomar el verde rojizo de la luz del bronce y permanecer inmóviles en el hondo silencio de la tarde. Se vio tendido en la hierba, junto al endrino. Y en el camino que ascendía se vio venir hacia él. Se miró al mismo tiempo en dos lugares distintos, esperándose. Vio como su imagen alzó el brazo y le saludó con alegría. Narciso parecía esperarle, ni siquiera se puso de pie. Las dos figuras se abrazaron y se miraron. - ¿Quién eres?_- preguntó Narciso con desgano, casi con frialdad. La figura le miró con malicia y Narciso se rió (9).

En ese instante, una ninfa que por amor lo buscaba entre los matorrales dio con él; al llamarlo por su nombre, interrumpió la extraña visión. Algunas frases y un beso intercambian; luego, Narciso se retira. Ahora bien, el Narciso que avanza por la montaña es uno desde la perspectiva de la ninfa que lo observa y dos para sí y para el lector: «Él se alejó, ella lo vio partir, lo vio caminar despacio. Y losdos hombres caminaron en silencio» $(26)^{9}$.

Como cualquier otro género o hipogénero literario, el relato fantástico tiene leyes que lo gobiernan en tanto forma narrativa convencional; éste trata específicamente

de transformar en discurso (realzar) el hecho de que aquello que en un principio parece improbable, extraño y sobrenatural es verosímil, probable y totalmente organizado. De esta manera, la organización de la materia, es decir, el choque conflictivo de dos formas de contenido, una real y otra irreal, se ve respondida como un eco por la organización de la forma ${ }^{10}$.

9. Los destacados son nuestros, tienen el propósito de enfatizar los formantes expresivos que marcan la diferencia entre la percepción. primero. del ser individual y. segundo, del doble. El cambio entre las formas del singular $y$ las del plural está en la base de este artificio narrativo que introduce. al cambiar el número. la duplicación: además, de que altera la organización sintagmática del texto, convirtiéndola en típica manıfestación del relato fantástico.

10. Michel Lord. "La organızación sintagmática del relato fantástico" en Antón Risco. Ignacio Soldevila y Arcadio López-Casanova (eds.). El relanofantásurco. Historia y sistema (Salamanca: Colegio de España. 1998) 14-15. 
Esta alteración suscita en el texto dos problemas que se conectan y han de resolverse si se procura comprender la narración, a saber: en primer lugar, la presencia de lo fantástico; en segundo término, el desdoblamiento.

Lo fantástico, ha escrito Todorov ${ }^{11}$, se define por la duda. Ante la aparición de un ser sobrenatural o la introducción de algún suceso inexplicable en el relato, el lector se ve movido a integrarse en el mundo de los personajes, a ser parte de la apreciación ambigua de los acontecimientos en función de esa inquietante extrañeza que despiertan tales intromisiones en el orden lógico de la cotidianidad; lo ominoso fascina, el libro se revela como mundo psicológico, como escenario para la comedia de las pasiones humanas.

La presencia de este contenido psíquico en la literatura demanda, como algo consubstancial, inquisiciones en torno a la noción de lo humano; en diversos sentidos, apuntan hacia la idea de sujeto. Cuando se discute sobre los problemas de lo fantástico y el doble, se discute, inevitablemente, sobre el sujeto. Todo antagonismo o escisión, la creación y el arte, cualquier fenómeno especular, la aparición de seres y monstruos antípodas, el cambio, la introspección, forman parte de las maneras en que se formula el tema del doble; abundan los ejemplos. Ciertamente, la presencia del doble como motivo artístico puebla las páginas de la literatura; sin duda, tal incidencia en la imaginación creadora responde a movimientos de la conciencia, estos movimientos despiertan y explican sentimientos que han sido objeto de la represión ${ }^{12}$.

Aún cuando el asunto tiende, por lo demás, hacia el ámbito de lo extraordinario, su vínculo con la realidad profunda de la conciencia es firme. Freud describió los mecanismos de funcionamiento psíquico que participan en la creación literaria; en este sentido, los asuntos que trata la literatura. la capacidad productiva misma, están estrechamente relacionados con los conflictos mentales del hombre

11. Para una definición ya tradicional de lo fantástico, ver Tzvetan Todoros. Introducción a la literatura fantástic a (Buenos Aires: Tiempo Contemporáneo. 1972) 33-52.

12. José Guimón. Psicoanálisis y litératura (Barcelona: Kairós. i993) 35. 
observados en el estudio clínico; la cultura y la neurosis hermanan a los diferentes individuos que componen la sociedad, gracias a éstas, el inconsciente del escritor se conecta con el del lector.

En la historia de los motivos que inspira la literatura y, por encima de ésta, en la organización estructural de las letras occidentales, el tema del doble ocupa un sitio sobresaliente. La elaboración estética de la dualidad, mediante la indagación literaria acerca del Yo y el Otro, de la identidad y la alteridad, halla en el desdoblamiento una singular manera de expresar la oposición y complementariedad de los contrarios. El régimen de la antítesis ha sido objeto de estudio angular por parte de diferentes disciplinas, entre éstas: la filosofía, la antropología, las ciencias de la comunicación, el psicoanálisis y la sociología. Ya en las doctrinas de los pensadores de la Antigüedad clásica se aprecia tal línea de reflexión; en las preocupaciones abordadas por Heráclito y Platón se manifiesta explícitamente. De acuerdo con Bargalló:

El desdoblamiento quizás no suponga más que una metáfora de esa antítesis o de esa oposición de contrarios, cada uno de los cuales encuentra en el otro su propio complemento; de lo que resultaría que el desdoblamiento (la aparición del Otro) no sería más que el reconocimiento de la propia indigencia, del vacío que experimenta el ser en el fondo de sí mismo y de la búsqueda del Otro para intentar llenarlo, en otras palabras, la aparición del Doble sería, en último término, la materialización del ansia de sobrevivir frente a la amenaza de la muerte ${ }^{13}$.

La aparición del doble obedece a una serie de procesos de orden psíquico, la conciencia acerca de la dualidad inherente al sujeto surge como el resultado de un encuentro repentino, de la experiencia

13. Juan Bargalló Carraté. "Hacia una tipología del doble: el doble por fusión. por fisión y por metamorfosis" en Juan Bargalló led. ). Identidad y alteridad: aproximación al te'ma del doble' iSevilla: Alfar. 1994) 11. 
de lo otro dentro de sí. En «Narciso», la llegada del doble posibilita el contacto con los demás, despierta niveles insospechados de conciencia con respecto al mundo; poco tiempo después de esta transformación, el doble enferma y muere:

Esa tarde, cuando Narciso regresó, encontró al hombre muerto, tendido bajo el árbol, todo cubierto de hojas. Quedó pálido. Cavó una fosa angosta y depositó el cuerpo sin vida; fue al valle y trajo flores blancas y las depositó junto al cadáver. Y antes de partir le besó en la frente. Las ninfas y los faunos encontraron una fosa vacía, llena de flores blancas (30-31).

Posteriormente, Narciso también muere; la desaparición de su doble se debe entender como un anuncio. Ahora bien, más allá de esta realidad, Narciso y el doble coinciden de nuevo; tras la muerte, en otro espacio, ambos entablan un diálogo acerca del amor y la vida. Las confesiones los llevan hacia una nueva revelación: existe otro hombre semejante a ellos en una caverna cercana. Al encontrarse con él, descubren algo que les causa horror: es un viejo enfermo y horrible, ciego y sordo, un viejo que no pudo soportar el paso de los años y el medrar de su belleza, un hombre, en suma, que decidió, como ellos, morir siendo hermoso y, sin embargo, resulta aberrante.

De nuevo, la mirada desempeña una función primordial por cuanto los jóvenes se contemplan en el viejo; de esta manera, la singular leyenda acerca del designio sufrido por ese hombre les provee un espejo donde observan sus propias intenciones y futuro. La abrupta verdad provoca el silencio.

La identidad, pues, resulta descabellada en tanto afán de permanecer; el desear ser siempre lo mismo se concibe como una amenaza para el individuo; los graduales develamientos persuaden a Narciso, le demandan una actitud de apertura y tolerancia hacia los demás y hacia sí; de cierta manera, le impulsan hacia el reconocimiento de su mortalidad: «No, no es un dios» (34), exclama Narciso ante la 
ruina de ese otro cuerpo que sabe suyo. Frente a lo único e inmutable, los personajes que componen el retablo de Luzbel discurren por los caminos de lo múltiple y el cambio; en algunas ocasiones, se convierten en apología de la libertad; en otras, en símbolos del ansia por la caída que comparte todo lo humano; en fin, son seres acechados por la perfección de los mundos irreales o de los paraísos artificiales, seres que buscan descanso.

Probablemente me equivoque, pero creo que Luzbel es uno de los textos que inaugura el discurso nacional acerca de lo insólito, con escasas incursiones hasta la fecha por lo demás. Basta recordar que un modelo prevalece en la escritura de nuestros prosistas, la referencialidad. A modo de principio constitutivo:

La organización total del discurso nacional define lo que se entiende por la «nación costarricense». Pero esta operación textual es pronto olvidada; gracias a este olvido, se concibe lo nacional como una esencia fijada para todo discurso verdaderamente «costarricense», es decir, se lo convierte en un referente obligado. Así, el funcionamiento del discurso nacional muestra sus diferentes operaciones ideológicas de adecuación del discurso literario al referente «nación» ${ }^{14}$.

Este proceso instituye una convención en torno a la literatura costarricense, por cuanto delimita una relación entre las instancias de producción y los destinatarios: se supone que ambos, escritor y lector, se hallan en un mismo espacio común, la geografía patria; además, comparten las particularidades étnicas, culturales e históricas de una comunidad, se amparan bajo una misma identidad. Por consiguiente, la labor del autor presume una especie de mimesis ad infinitum de lo nacional, en tanto que leer es un acto de reconocimiento que fortifica

14. Flora Ovares y otros. La casa paturna. Escritura y nacion en Costa Rica (San José: Editorial de la Universidad de Costa Rica. 1993) 5. 
los lazos con una cosmovisión determinada - la propia - y la pertenencia a una comunidad específica ${ }^{15}$. Desde finales del siglo XIX y durante buena parte de la primera mitad del XX, se escriben historias con el propósito de ser leídas en familia, éstas fungen como una clase de espejo donde los costarricenses se miran.

Ahora bien, la crítica literaria está también vinculada al ámbito de acción de la lectura y, por tanto, se adscribe de ordinario a tal proceso; la crítica tradicional sistematizó el discurso y clasificaba como parte de la literatura nacional a aquellos textos referentes a la nación; por el contrario, «Cuando aparece un texto que, al desconocer ese espacio común, rompe con la convención, tanto éste como su autor resultan desconocidos como elementos representativos del discurso nacional» ${ }^{16}$.

Poco a poco, cobra vigencia una línea de entendimiento para el análisis de las letras costarricenses; ésta se funda en el accionar centrípeto del discurso identitario; de esta manera:

Nación y enajenación se confunden en este esfuerzo por elaborar un modelo metonímico del ser nacional que permita a todos los habitantes del territorio costarricense, pertenecientes a regiones geográficas relativamente aisladas, con formaciones étnicas, sociales y culturales heterogéneas, imaginarse comouna unidad homogénea, como un sujeto unitario desde cuyo centro se expresa una identidad común, se ordena una realidad compartida y se define su organización, sus límites y contornos ${ }^{17}$.

Harold Bloom ${ }^{18}$ recuerda que el canon obedece, en sus orígenes, menos a un asunto de autoridad que a un problema didáctico, que

\footnotetext{
15. idem.

16. İdem.

17. Álvaro Quesada Soto. Uno y los orros: Identidad y literatura en Costa Rica 1890-1940 (San José: Editorial de la Universidad de Costa Rica. 2002) 18.

18. Harold Bloom. "Una elegía al canon”. El canon occidental (Barcelona: Anagrama. 1995) 25.
} 
deriva ineludiblemente de una condición natural: se cuenta con poco tiempo — vita brevis - para la lectura. ¿Qué se debe leer entonces?: una cuestión que se imponía y se impone como prioritaria a las instituciones de enseñanza, encargadas de transmitir el legado cultural.

Múltiples circunstancias afectan el modo en que se lee; algunas por domésticas se han vuelto imperceptibles. Sin embargo, como lo señala Kermode ${ }^{19}$, la interpretación está supeditada a la injerencia de las instituciones culturales; la crítica literaria interpreta los textos literarios a partir de un conjunto de conocimientos tácitos, es decir, de un paradigma que asienta los criterios para la exégesis, elaborado por una comunidad profesional con autoridad para delimitar tópicos y valoraciones válidas. El canon crítico implica una selección necesaria por cuanto tiene la finalidad de constituir un corpus de estudio, susceptible de ser interpretado mediante una serie de postulados, unitario, emblemático y completo; conveniente, en lo didáctico y estético, a la hora de transmitirlo mediante la enseñanza - en especial, de los sucesores - como representación de la cultura; una serie de obras donde se reconoce la variedad de principios que definen la mentalidad costarricense.

La canonicidad más que una convocatoria al resentimiento, impone un debate; sin duda, se debe reconocer que gran parte de la literatura y la crítica tiene sesgos, sean de género, epistemológicos o raciales; no obstante, el canon mismo obliga a una búsqueda de los cimientos del campo literario, pues evoca una impresión de la cual no se puede disponer si se desea un entendimiento completo; es la impresión brindada por el encuentro con los límites. En este sentido Harris escribe: «[...] ninguna selección de textos que pueda encajar en un curso de literatura, o incluso en la totalidad de los que configuran una licenciatura, puede proporcionar toda esa información de manera adecuada» $^{20}$.

19. Frank Kermode. «El control institucional de la interpretación» en Enric Sullá (comp.). El canon iircraro (Madrid: Arco/Libros. 1998) 91-95.

20. Wendell $v$. Harris. "La canonicidad». El (anon literario (Madrid: Arco/Libros. 1998) 60. 
El concepto de literatura canonizada sirve no para explicar el desconocimiento de Luzbel, ni su exclusión del discurso nacional, si con propiedad puede denominarse así — se acerca más al desconocimiento-, no explica pues, se indicaba, sino marginalmente y a modo de especulación se ignoran con exactitud las causas de la marginalidad de esta obra. Quedan por explorar las condiciones de producción (políticas editoriales, comercio, escasa difusión, poco interés por la narrativa costarricense en una época donde brillan las luces hispanoamericanas merced a la nueva novela y el éxito en las ventas), tantas y tan diversas circunstancias difíciles de precisar, escurridizas al ojo del comentarista. Con todo, resulta bastante difícil creer que tal situación obedezca a una lógica institucional o a un problema de interpretación. Sin embargo, Luzbel es un libro que demanda una revisión de los elementos constitutivos del campo literario; la noción de literatura canonizada o no canonizada apunta hacia la comprensión de un concepto de base: lo literario funciona en el seno de la socie$\mathrm{dad}^{2 \mathrm{l}}$; más que modelos literarios, el canon implica modelos cognitivos, modelos de aprehensión. Esta línea de investigación da la clave de interpretación para Luzbel; este libro cuestiona, a través de la lectura aguda, la concepción tradicional de literatura costarricense. ¿Qué integra el discurso nacional: los textos que hablan explícitamente sobre Costa Rica o aquellos que participan de sus preocupaciones aún cuando no describen ambientes o situaciones patrias ni narran los avatares de los seres autóctonos? ¿En qué medida ceden las fronteras nacionales durante la segunda mitad del siglo XX, en qué medida la literatura costarricense evidencia este proceso? ¿Las preguntas sobre la identidad han variado o han desaparecido: cómo se percibe el país, por encima de las máscaras de lo particular, en el nivel de las indagaciones occidentales? ¿De qué forma penetran la literatura los estudiosos: a partir de lo visible o por medio de lo epistemológico?

21. Fernando Gómez Redondo, La crítica literaria del siglo XX (Madrid: EDAF, 1999) 331. 
Sin duda, tales interrogantes escapan a lo que en estas páginas pueda of recerse; páginas que por lo demás hacen recuento de una experiencia y no del ensayo de propuestas. Buen tino hay en creer que la lectura redime las sombras que habitan los libros; ella nos acusa de desatenciones, ¿cabe alegato alguno ante el olvido? 